Original Research
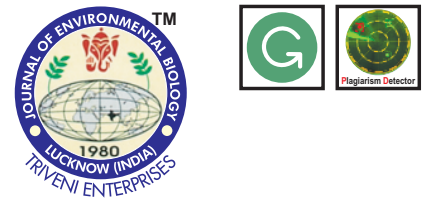

\title{
Ultrastructural studies of Puntius shalynius an endemic and threatened hill stream fish
}

\section{Authors Info}

\section{Manorama* and} S. N. Ramanujam

Fish Biology Laboratory, Department of Zoology, School of Life Sciences, North Eastern Hill University, Shillong - 793 022, India

*Corresponding Author Email : maisnamanorama@gmail.com

Key words

Electron microscopy,

Intestine,

Puntius shalynius

Publication Info

Paper received : 06.07.2016

Revised received : 15.11.2016

Re-revised received : 20.01.2017

Accepted : 16.02.2017

\section{Abstract}

Aim : Shalynai fish, Puntius shalynius is an inhabitant of freshwater, endemic and threatened hill stream fish of North-East India. The present work aimed to study the ultrastructural and functional characteristics of $P$. shalynius intestine, as addition to studies on nutritional requirement. This fish is considered an important species for ornamental exploitation.

Methodology : A total of five samples were collected from Umiam river, Meghalaya and transported to the laboratory for Transmission Electron Microscopy. Samples from intestine were cut into small pieces, fixed in Karnovsky's fixative, washed in $0.1 \mathrm{M}$ sodium cacodylate buffer and examined under an electron microscope.

Results : The electron microscopy of the anterior intestine from five individuals indicated that the enterocytes were elongated resting on basement membrane and covered apically with uniform microvilli. The apical cytoplasm, just below the microvilli, had no cellular organelles and formed the terminal web. Numerous mitochondria were seen along with other cell organelles such as ribosomes and nucleus. Cellular ultrastructural features were associated with digestive functions.

Interpretation : The ultrastructural characteristics of $P$. shalynius intestine showed that a functional specialization exist in this fish also like other teleostean species, a common approach for active digestion in the lack of definite enzymes. The existence of microvilli seems to be important for absorptive function of the cells and enterocytes seems to function primarily in lipid absorption.

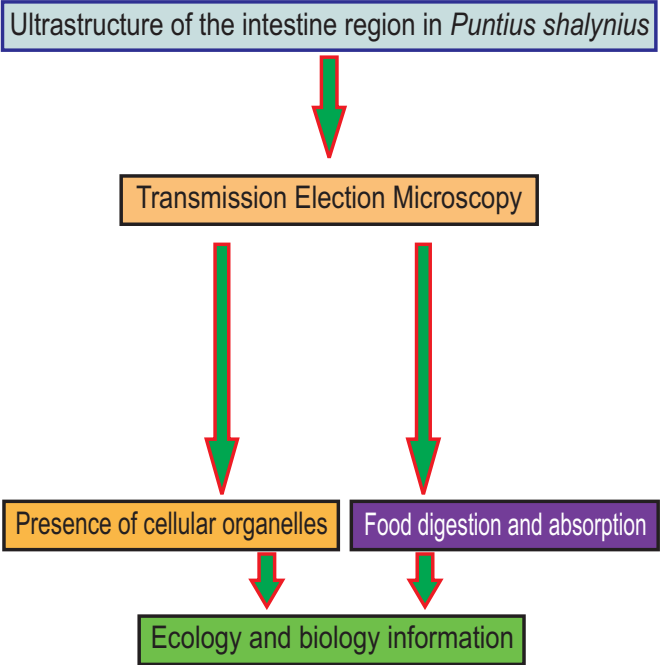




\section{Introduction}

Puntius shalynius (Yazdani and Talukdar, 1975), a minor carp belonging to the order Cypriniformes and family Cyprinidae is a hill stream, endemic and economically important species for its ornamental value. This species has restricted distributional range found in Meghalayan rivers namely, Umiam, Umkhen, Umtrew, Umryleng Myntdu, Myntang, Umshing and Kynshi. These rivers belong to four different districts of Meghalaya viz. Ribhoi, Jaintia Hills, East Khasi Hills and West Khasi Hills. It is a small hill stream fish where the maximum growth of the adult is about $6.3-7.0 \mathrm{~cm}$ in length. The body of the species is characterized by short, compressed dorsal profile little convex than the ventral profile. Minute white tubercles present on the head of males are distinguishing features from that of females (Manorama and Ramanujam, 2016). The habitat of the fish is situated in between 1000 to $1400 \mathrm{~ms}$ which might be the possible reason for restricted distributional range of the species (Manorama et al., 2014). P. shalynius, previously an abundant fish found wild in Meghalaya, has now been categorized as "vulnerable" (IUCN, 2015). Earlier it was reported that $P$. shalynius feeds on animal matter, detritus and algae (Manorama and Ramanujam, 2011), but there is no information on the ultrastructure of this fish which is crucial for diagnosing intestinal diseases and formulating suitable feeds of this fish. Fish digestive tract shows remarkable differences in morphology and functions in various species and plays an important role in the digestion and absorption of dietary nutrients (Murray et al., 1996). The overall gastrointestinal morphology is related to different feeding habits including the nature of the food and frequency of food intake, as well as taxonomy, body size and shape (Boglione et al., 1992; Domeneghini et al., 1999). The alimentary canal of teleostean fishes has been widely studied (MacDonald, 1987; Kuperman and Kuzmina, 1994; Domeneghini et al., 2002; Khojasteh et al., 2009; Camacho et al., 2011) and described morphologically to determine the function of many specialized anatomical structures (Cataldi et al., 1987). In many fish species, the anatomy of intestine has been studied which are important for aquaculture, recreation and aquarium (Caceci and Hrubec, 1990).

In the present study, the anatomical structures of $P$. shalynius, collected from Umiam river, Meghalaya, were studied for ascertaining digestive functioning. To the best of our knowledge, limited work has been reported on ultrastructure of digestive tract of $P$. shalynius having ornamental and food value. The objective of the present study was to describe the structure of the intestine of $P$. shalynius, an important hill stream and threatened species in Meghalaya, India.

\section{Materials and Methods}

Sample collection : P. shalynius, measuring 6.0 to $7.0 \mathrm{~cm}$ in length comprising of both sexes, were collected from Umiam river, Meghalaya, India. The study area is situated at an altitude of
$1020 \mathrm{msl}$ and falls at an intersection of $25^{\circ} 40^{\prime} \mathrm{N}$ latitude and $91^{\circ} 54^{\prime} \mathrm{E}$ longitude. The samples were collected with the help of local fishermen and transported to the fish laboratory in live condition. After being taken to laboratory, fish were sacrificed, dissected and the entire digestive tract was exposed. The samples of intestinal region were taken out for further study.

Due to poor picture quality of histological sections, we excluded histology from the present study.

Transmission electron microscopy : Five individuals were used for Transmission Electron Microscopy (TEM). Samples from anterior and posterior intestine were cut into small pieces $(2 \mathrm{~mm})$ with the help of simple microscope and sharp scissor. Extreme care was taken in order to cut tiny pieces of the intestine and fixed at $4^{\circ} \mathrm{C}$ in modified Karnovsky's fixative for $4 \mathrm{hrs}$. The fixed samples were washed in $0.1 \mathrm{M}$ sodium cacodylate buffer (Watson, 1958). Post fixation was carried out in $1 \%$ osmium tetroxide in the same buffer for $1 \mathrm{hr}$ at $4^{\circ} \mathrm{C}$. The samples were dehydrated in ascending grades of acetone and cleared in propylene oxide. It was then embedded in Araldite medium. Ultrathin sections of $70 \mathrm{~nm}$ thickness were collected on copper grids and stained with $50 \%$ alcoholic saturated uranyl acetate for ten minutes at room temperature followed by lead citrate solutions. Here, lead citrate was used for staining ultrathin sections because it is stable for long time and does not contaminate the sections with unnecessary precipitate (Reynolds, 1963). The samples were analyzed under an electron microscope with JEM 2100.

\section{Results and Discussion}

Study on the digestive tract and different feeding habits of fish residing in various water depth provide useful ecological and biological information. In the present study, the intestinal sample of $P$. shalynius was examined following the standard protocol and anatomy resembles that of other teleostean fishes. Similar studies were reported by Arellano et al. (2002) on the anterior and posterior intestine of Solea Senegalensis; Dai et al. (2007) made a detail ultrastructural study of the digestive tract of Monopterus albus; Khojasteh et al. (2009) worked on transmission electron microscopy collected from different fragments of intestine in Oncorhynchus mykiss and Namulawa et al. (2015) described transmission electron microscopy of the intestine of Lates niloticus.

TEM of the intestine revealed that the columnar epithelial cells or enterocytes were elongated resting on the basement membrane (Fig. 1A). Findings on enterocyte of the intestine in $P$. shalynius are congruent with that of previous report in Salvelinus alpinus (Olsen et al., 1999). The apical cell membrane showed numerous regularly arranged cytoplasmic projections, microvilli, which formed the brush border (Fig. 1C). These microvilli were covered by glycocalyx and the upper parts of some of them were dense and formed spherical bleb called capitulum (Fig. 1B). The 
existence of microvilli is related to the absorptive function of the cells (Grau et al., 1992). The tip of microvilli in P. shalynius possess capitula which may increase the apical surface and intensify penetration. (Athikesavan et al., 2006). Similar observations were reported in the intestine of Hypophthalmichthys molitrix and Labeo niloticus (Naguib et al., 2011). The apical cytoplasm just below the microvilli had no cellular organelles and formed the terminal web. Invaginations of the apical plasma membrane were frequently seen among the microvilli forming the endocytotic channels. The enterocytes consisted of a few numbers of endocytotic channels which helps in uptake of protein macromolecules. This result is in confirmation with that of Khadse and Gadhikar (2017). The enterocytes were joined at the apical surface by typical junctional complexes
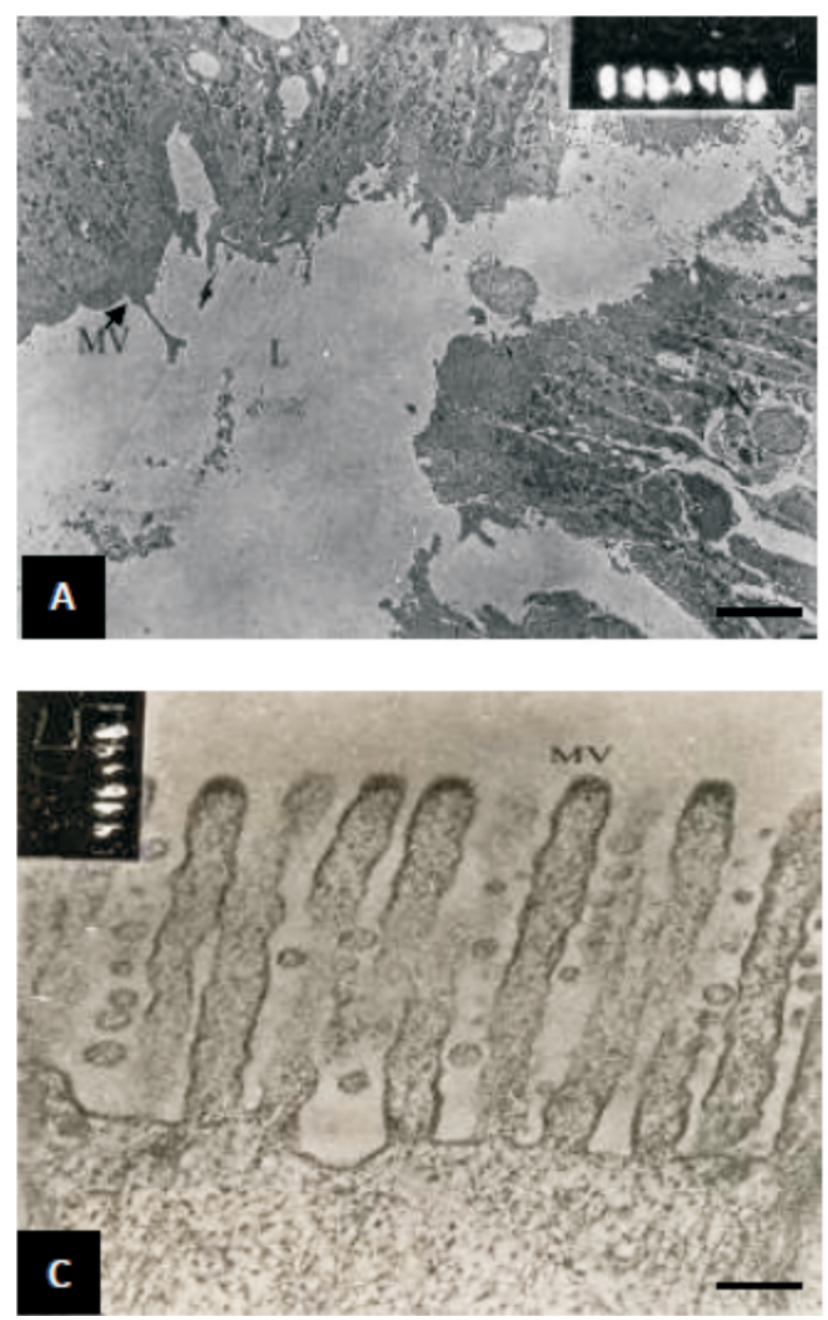

including the desmosomes (Fig. 1B). Kiliaan et al. (1996) suggested that the junctional complexes of the enterocytes of Carassius auratus may prevent the paracellular leakage of ions and macromolecules. It is well established that enterocytes are involved in lipid absorption (Houssain and Dutta, 1998). The mitochondria were numerous and polymorphic in shape (rounded, oval and elongated) distributed in the cytoplasm of epithelial cells. The inner mitochondrial membrane formed numerous lamellar cristae. The free ribosomes were abundant and scattered throughout the cell cytoplasm (Fig. 1D). The nuclei of enterocytes were large and oval in shape. The nuclear envelope was double membrane consisting of outer and inner nuclear membranes. Euchromatin was represented by pale granular areas of nucleoplasm, whereas heterochromatin was
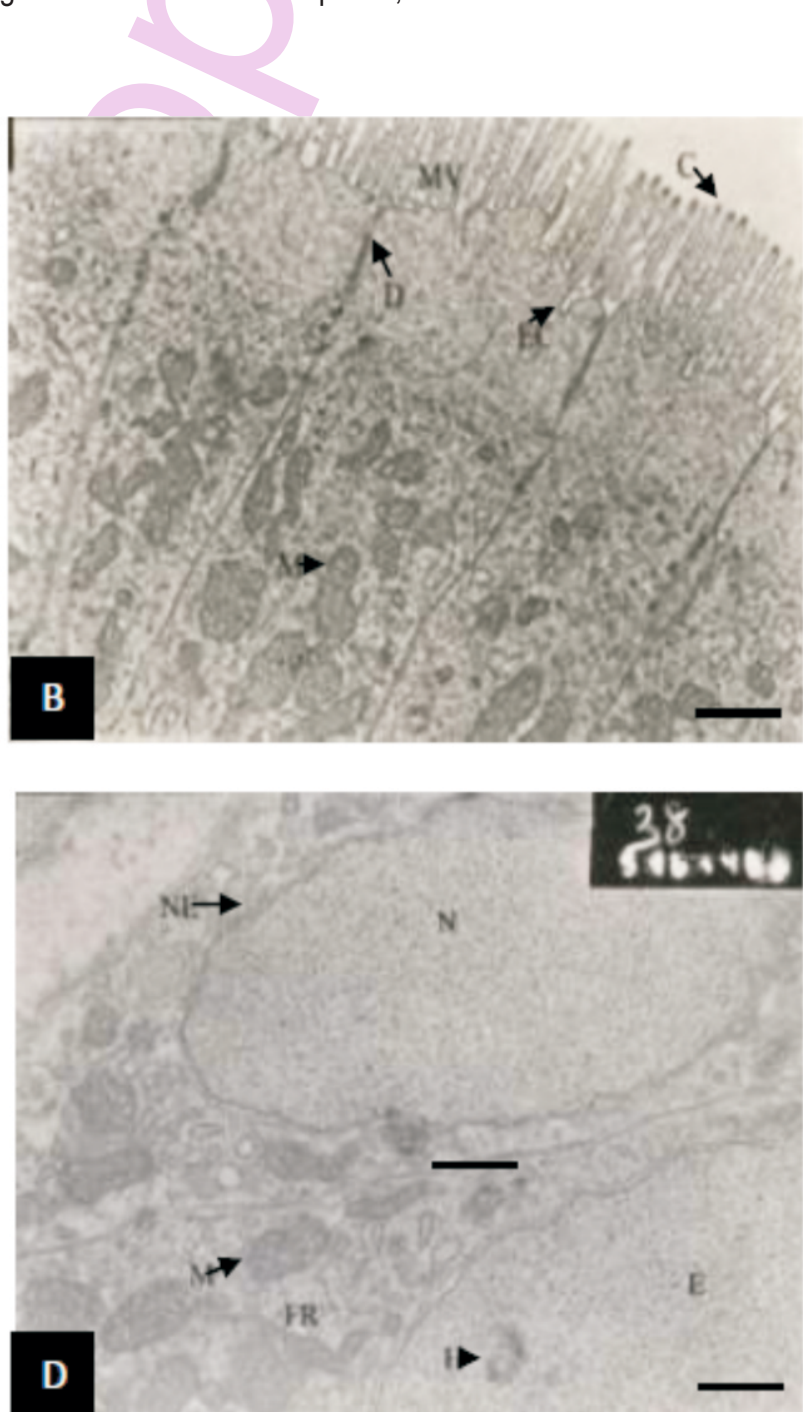

Fig. 1: TEM micrograph of cell types present in the intestine of $P$. shalynius; (A.) Inner layer of intestine with lumen (L), nucleus (N) and microvilli (MV).; (B.) Micrograph showing apical junctional complex desmosomes (D) with long microvilli (MV), capitulum (C), endocytotic channels (EC) and numerous scattered mitochondria (M) ; (C) Micrograph showing long structure of microvilli (MV) and (D) Micrograph showing nuclear envelope (NE), nucleus (N), heterochromatin $(H)$, euchromatin $(E)$, mitochondria $(M)$ and free ribosomes (FR) 
represented by small dark granular patches (Fig. 1D).

Stomach is absent in P. shalynius, which is similar to other cyprinid fish such as loaches (Venkat Appa Rao and Shukla, 2013) and gobies (Wolczuk et al., 2015). In fish, the absence of a stomach does not limit trophic preference leading to identical alimentary morphology susceptible of digesting many diets (Day et al., 2011). Unal et al. (2001) stated that true stomach of Chalcalburnus tarichi was absent and instead there was an expansion at intestine called the post-oesophageal swelling. Mir and Channa (2010) reported the presence of intestinal bulb in Schizothorax curvifrons which lacks stomach. The presence of intestinal bulb in $P$. shalynius is similar to the findings of other teleostean fish such as Anarhichas lupus (Helberg and Bjerkas, 2000), Misgurnus mizolepis (Park and Kim, 2001) and Mystus cavasius, Oreochromis niloticus and Gudusia chapra (Ghosh and Chakrabarti, 2015). It is worth mentioning that the intestine of teleostean fish exhibits the site of food digestion and absorption.

In conclusion, the present study on anatomical structures of $P$. shalynius provide information on digestion and absorption of nutrients in relation to feeding habits. More studies should be carried out for better understanding of the processes of digestion in $P$. shalynius, highly endemic and threatened fish species of North-East India. The results presented in this study may be considered as a baseline for subsequent studies on the intestinal bulb of different teleosts.

\section{Acknowledgments}

Authors are thankful to the North Eastern Hill University, Shillong for financial support under University with Potential for Excellence scheme of UGC to Life Sciences, Council of Scientific and Industrial Research (CSIR), Ministry of Environment and Forest (MoEF) and Head of Department of Zoology for giving permission to carry out the experiment and also for providing all the research facilities. Anonymous referee and Editor-in-Chief, Journal of Environmental Biology are greatly acknowledged for helpful comments and suggestions.

\section{References}

Arellano, J.M., V. Storch and C. Sarasquete: Ultrastructural study on the intestine of Senegal sole, Solea senegalensis. J. Appl. Ichthyol., 18, 154-158 (2002).

Athikesavan, S., S. Vincent, T. Ambrose and B. Velmurugan: Nickel induced histopathological changes in the different tissues of freshwater fish, Hypophthalmichthys molitrix (Valenciennes). J. Environ. Biol., 27, 391-395 (2006).

Boglione, C., B. Bertolin, M. Russiello and S. Cataudella: Embryonic and larval development of thicklipped mullet (Chelon labrosus) under controlled reproduction conditions. Aquaculture, 101, 349-359 (1992).

Caceci, T. and T.C. Hrubec: Histology and ultrastructure of the gut of the Black Mollie (Poecilin spp.), a hybrid teleost. J. Morphol., 204, 265280 (1990).
Camacho, S., R. Carmona, J.I. Llorente, A. Sanz, M. Garcia-Gallego, A. Domezain, N. Dominguez and M.V. Ostos-Garrido: Stomach development in the sturgeon Acipenser naccarii: Histoenzymatic and ultrastructural analysis. J. Appl. Ichthyol., 27, 693-700 (2011).

Cataldi, E., S. Cataudella, G. Monaco, A. Rossi and L. Tancioni: Astudy of the histology and morphology of the digestive tract of the seabream, Sparus aurata. J. Fish. Biol., 30, 135-145 (1987).

Dai, X., M. Shu and W. Fang: Histological and ultrastructural study of the digestive tract of rice field eel, Monopterus albus. J. Appl. Ichthyol., 23, 177-183 (2007).

Day, R.D., D.P. German, J.M. Manjakasy, I. Farr, M.J. Hansen and I.R. Tibbetts: Enzymatic digestion in stomachless fishes: How a simple gut accommodates both herbivory and carnivory. J. Comp. Physiol., B 181, 603 (2011).

Domeneghini, C.S., S. Arrighi, G. Radaelli, G. Bosi and G.S. Mascarello: Morphological and histochemical peculiarities of the gut in white sturgeon, Acipenser transmontanus. Eur. J. Histochem., 43, 135145(1999).

Domeneghini, C., G. Radaelli, G. Bosi, S. Arrighi, A. Di Giancamillo, M. Pazzaglia and F. Mascarello: Morphological and histochemical differences in the structure of the alimentary canal in feeding and runt (feed deprived) white sturgeons (Acipenser transmontanus). J. Appl. Ichthyol., 18, 341-346 (2002).

Ghosh, S.K. and P. Chakrabarti: Histological and histochemical characterization on stomach of Mystus cavasius (Hamilton), Oreochromis niloticus (Linnaeus) and Gudusia chapra (Hamilton): Comparative study. J. Basic Appl. Zool., 70, 16-24 (2015).

Grau, A., S. Crespo, M.C. Sarasquete and M.L. Gonzalez de Canales: The digestive tract of the amberjack Seriola dumerili, Risso: A light and scanning electron microscope study. J. Fish. Biol., 41, 287303 (1992)

Helberg, H. and I. Bjerkas: The anatomy of the oesophagus, stomach and intestine in common wolfish (Anarhichas lupus L.): A basis for diagnostic work and research. Acta. Vet. Scand., 41, 283-297 (2000).

Houssain, A.M. and H.M. Dutta: Assessment of structural and functional similarities and differences between caeca of the bluegill. J. Fish. Biol., 53, 1317-1323 (1998).

IUCN : IUCN Red List of Threatened Species, 2015: Version 2015.2. Gland: International Union for the Conservation of Nature and Natural Resources. http://www. iucnredlist. org/apps/ redlist/ details/ 19488/0 (2015)

Khadse, T.A. and Y.A. Gadhikar: Histological and ultrastructural study of intestine of Asiatic knife fish, Notopterus notopterus. Int. J. Fish. Aquat. Stud., 5, 18-22 (2017).

Khojasteh, S.M.B., F. Sheikhzadeh, D. Mohammadnejad and A. Azami: Histological, histochemical and ultrastructural study of the intestine of Rainbow Trout (Oncorhynchus mykiss). World. Appl. Sci. J., 6, 1525-1531 (2009)

Kiliaan, A.J., G. Scholten, P.B. Bijlsma, K. Dekker and J.A. Groot: Influence of forskolin and carbachol on intestinal absorption of horseradish peroxidase in the goldfish (Carassius auratus). Cell. Tissue. Res., 285, 51-56 (1996).

MacDonald, N.L.: An electron microscopic examination of the gastrointestinal epithelium in Dover sole, Solea solea (L). J. Fish. Biol., 31, 27-36 (1987).

Manorama, M. and S.N. Ramanujam: Length-weight relationship of freshwater fish, Puntius shalynius Yazdani and Talukdar (Cypriniformes: Cyprinidae), in Meghalaya, India. J . Appl. 
Ichthyol., 27, 1404-1405(2011).

Manorama, M., S.N. Ramanujam and S. Dey: Scanning electron microscopy of some vital structures of Puntius shalynius Yazdani and Talukdar 1975, an endemic hill-stream fish of North East India. J.Adv. Microsc. Res., 9, 1-7 (2014).

Manorama, M. and S.N. Ramanujam: Morphometric, meristic studies and conservation of the vulnerable fish, Puntius shalynius Yazdani and Talukdar (Actinopterygii: Cypriniformes) in the Umiam river, North-East India. Indian J. Fish., 63, 113-116 (2016).

Mir, I.H. and A. Channa: A scanning electron microscopic examination of the intestinal tract of the snow trout, Schizothorax curvifrons Heckel. J. Fish. Aquat. Sci., 5, 386-393 (2010).

Murray, H.M., G.M. Wright and G.P. Goff: A comparative histological and histochemical study of the post-gastric alimentary canal from three species of pleuronectids, the Atlantic halibut, the yellowtail flounder and the winter flounder. J. Fish. Biol., 48, 187-206 (1996).

Naguib, S.A.A., H.A. El-Shabaka and F. Ashour: Comparative histological and ultrastructural studies on the stomach of Schilbe mystus and the intestinal swelling of Labeo niloticus. J. Am. Sci., 7, 251-263 (2011).

Namulawa, V.T., C.D. Kato, E. Nyatia, J. Rutaisire and P.J. Britz: Transmission electron microscopy of the gastrointestinal tract of Nile perch Lates niloticus. Int. J. Morphol., 33, 751-758 (2015).

Olsen, R.E., R. Myklebust, T. Kaino and E. Ringo: Lipid digestibility and ultrastructural changes in the enterocytes of Arctic char (Salvelinus alpinus L.) fed linseed oil and soybean lecithin. Fish. Physiol. Biochem., 21, 35-44 (1999).

Park, J.Y. and I.S. Kim: Histology and mucin histochemistry of the gastrointestinal tract of the mud loach, in relation to respiration. $\mathrm{J}$. Fish. Biol., 58, 861-872 (2001).

Reynolds, E.S.: The use of lead citrate at high $\mathrm{pH}$ as an electron opaque stain in electron microscopy. J. Cell. Biol., 17, 208-212 (1963).

Stroband, H.W.J. and F.M.H. Debets: The ultrastructure and renewal of the intestinal epithelium of the juvenile grasscarp, Ctenopharyngodon idella (Val.). Cell. Tissue. Res., 187, 181-200 (1978).

Unal, G., O. Cetinkaya, E. Kankaya and M. Elp: Histological study of the organogenesis of the digestive system and swim bladder of the Chalcalburnus tarichi Pallas, 1811 (Cyprinidae). Turk. J. Zool., 25, 217-228 (2001).

Venkat Appa Rao, N. and R.K. Shukla: Distribution of gastrin immune reactive cells in the alimentary canal of a stomachless hill stream loach, Lepidocephalus guntea (Hamilton): An immunohistochemical study. Proc. Natl. Acad. Sci., India, Sect. B Biol. Sci., 83,603(2013)

Watson, M.L.: Staining of tissue sections for electron microscopy with heavy metals. J. Biophys. Bichem. Cytol., 4, 475-478 (1958).

Wolczuk, K., J. Nowakowska, D. Plachocki and T. Kakareko: Histological, histochemical and ultrastructural analysis reveals functional division of the oesophagogastric segment in freshwater tubenose goby Proterorhinus semilunaris Heckel, 1837. Zoomorphology, 134, 259-268 (2015).

Yazdani, G.M. and S.K. Talukdar: A new species of Puntius (Cypriniformes: Cyprinidae) from Khasi and Jaintia Hills (Meghalaya), India. J. Bombay Nat. Hist. Soc., 72, 218-221 (1975). 